GEOTHERMAL POWER

\title{
Harnessing Hot Springs Around the World
}

from our Geomagnetism Correspondent

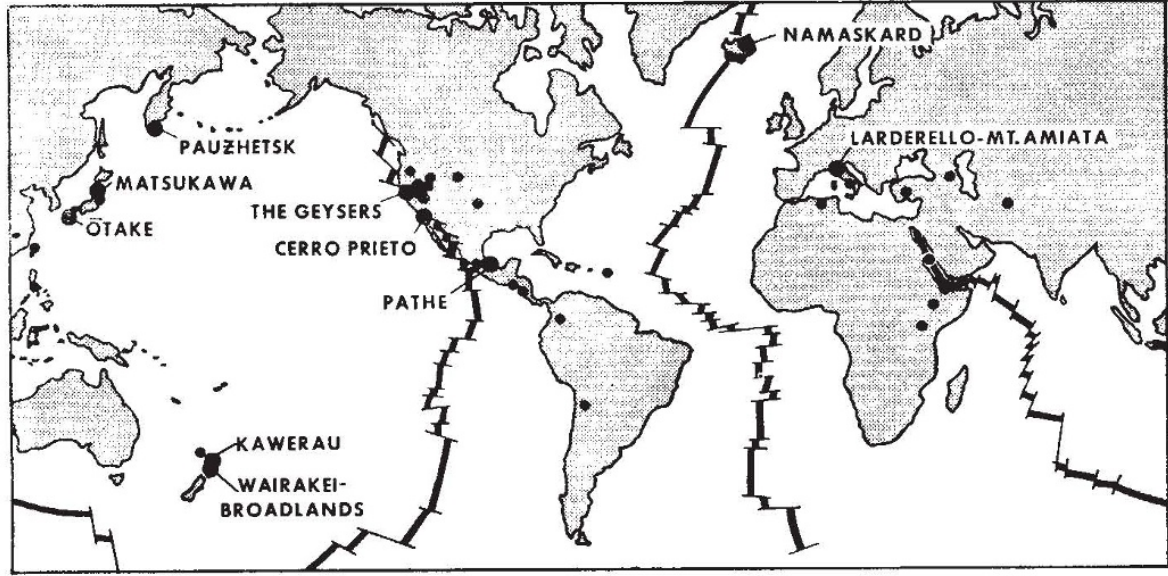

Geothermal areas of the world. Large circles, producing fields ; small circles, promising areas.

THE most energetic process taking place in the Earth today is the outward flow of heat through the Earth's surface. This happens everywhere, but certain regions have higher heat flows than others and some are potentially capable of supplying heat commercially. The nice thing about geothermal power is its cleanliness - the severity of pollution is much reduced compared with fossil fuels; but this is not to say there are no pollution problems at all. In the Salton Sea area of California, for example, where natural hot brines are used in heating systems the mineral content of the brine, about a quarter of all the dissolved salts, poses its own problems of waste disposal

Hot springs have been used for baths ever since Roman times at least, though the use of natural steam for the manufacture of electricity did not begin until early in the present century. The first commercial use of the Earth's heat took place at Larderello, Italy, in 1777 when borax was recovered from natural steam and hot water vents-a product which is still found there today. In 1905 , the world's first power generating station using natural steam energy was also established at Larderello. Iceland seems to have been the next place to develop geothermal energy for domestic and commercial purposes, for hot water energy was used there for space heating in 1925. In that year attempts were also made to harness geothermal steam in New Zealand, although no serious developments took place there until 1946 when the New Zealand government took over development of natural steam.

The world production of power from the Earth's natural heat now exceeds one million kilowatts, though even under current economic conditions this could probably be increased ten-fold. Larderello still leads in production $(400,000 \mathrm{~kW})$, followed by New Zealand (more than $170,000 \mathrm{~kW}$ ) and the United States $(83,000 \mathrm{~kW})$. And many other countries - for example, Algeria, Chile, Czechoslovakia, Hungary, China, France, Turkey, Kenya and the Soviet Union-are either searching for geothermal sources or are looking at how existing sources might be harnessed. In Japan, in particular, geothermal energy development has a high priority in national planning.

Geothermal resources in the United States were first investigated during the early 1920 s, though the first commercial wells were not drilled until 1955 in The
Geysers area, 75 miles north of San Francisco. Four wells drilled to depths of less than 1,000 feet began producing power in 1960 at the rate of about $12,500 \mathrm{~kW}$, though this capacity has since increased to $83,000 \mathrm{~kW}$. In the meantime, on December 24, 1970, Congress passed the Geothermal Steam Act which requires the Department of the Interior to list all land with geothermal resources as a first step to their development. The US Geological Survey has so far identified 1.3 million acres of land, primarily in the west, as being potentially suitable for geothermal development, the estimated steam reserves being equivalent to about $30,000 \mathrm{~mW}$ of electric power, or about 5 to 10 per cent of the power to be derived from fossil fuels in the same area.

\section{EVOLUTION}

\section{What Use is Sex?}

from our Population Genetics Correspondent IN his classic book The Genetical Theory of Natural Selection published in 1930, Sir Ronald Fisher briefly discussed what advantage is to be gained from sexual, rather than asexual, reproduction. Recently, this has been a controversial issue, and now Maynard Smith, in an article in the Journal of Theoretical Biology $(30,319 ; 1971)$ entitled "What Use is Sex?", describes computer simulations which essentially confirm Fisher's original conclusions.

Unfortunately, in the manner which was typical of him, Fisher never fully explained how he arrived at his conclusions. But his argument is basically as follows. If two advantageous mutations occur, they can only be incorporated into the same individual if sexual reproduction is available to bring the mutations together by the process of

\section{Spinodal Behaviour in an Alkali Feldspar}

SPINODAL decomposition has been observed in an alkali feldspar $(\mathrm{Na}, \mathrm{K}) \mathrm{Al}$ $\mathrm{Si}_{3} \mathrm{O}_{8}$, a common rock forming mineral, following heat treatment in the laboratory. In next Monday's Nature Physical Science, Owen and McConnell report that they have seen modulated structures using transmission electron microscopy and they show an example with a wavelength of $160 \AA$.

Similar structures are well known in metal, glass and oxide systems (C. Hilliard, Phase Transformations, ASM, $497 ; 1970$ ) and there have been several observations of modulated structures in natural feldspar and pyroxenes $(\mathrm{Ca}$, $\mathrm{Se}, \mathrm{Mg}) \mathrm{Si} \mathrm{O}_{3}$. But this is the first published report of the production of a modulated structure in a mineral under controlled hydrothermal conditions. Although the existence of spinodal decomposition has been inferred in many cases from the observations of modulated structures and the associated satellite reflexion in the fraction pattern, such structures could be produced by other mechanisms (for example, elastic energy or diffusion effects). Spinodal decomposition is associated with a negative diffusion coefficient and a specific variation in the modulation wavelength and amplitude with time and with temperature (J. W. Cahn, Trans. AIME, 242, 166 ; 1968). Conformation of a spinodal mechanism has only been achieved by quantitative small-angle $X$-ray scattering data in a very few systems. 